OPEN ACCESS

Edited by:

Usha Krishnan,

Sydney Children's Hospital, Australia

Reviewed by:

Anastassios Constantin Koumbourlis, George Washington University, USA

Yvonne Belessis,

Sydney Children's Hospital, Australia

*Correspondence:

Thomas Kovesi

kovesi@cheo.on.ca

Specialty section:

This article was submitted to Pediatric Gastroenterology, Hepatology and Nutrition, a section of the journal Frontiers in Pediatrics

Received: 26 October 2016 Accepted: 15 March 2017 Published: 03 April 2017

Citation:

Kovesi T (2017) Aspiration Risk and Respiratory Complications in Patients with Esophageal Atresia. Front. Pediatr. 5:62. doi: 10.3389/fped.2017.00062

\section{Aspiration Risk and Respiratory Complications in Patients with Esophageal Atresia}

\author{
Thomas Kovesi* \\ Children's Hospital of Eastern Ontario, University of Ottawa, Ottawa, ON, Canada
}

Chronic, long-term respiratory morbidity (CRM) is common in patients with a history of repaired congenital esophageal atresia, typically associated with tracheoesophageal fistula (EA/TEF). EA/TEF patients are at high risk of having aspiration, and retrospective studies have associated CRM with both recurrent aspiration and atopy. However, studies evaluating the association between CRM in this population and either aspiration or atopy have reported conflicting results. Furthermore, CRM in this population may be due to other related conditions as well, such as tracheomalacia and/or recurrent infections. Aspiration is difficult to confirm, short of lung biopsy. Moreover, even within the largest evidence base assessing the association between CRM and aspiration, which has evaluated the potential relationship between gastroesophageal reflux and asthma, findings are contradictory. Studies attempting to relate CRM to prior aspiration events may inadequately estimate the frequency and severity of previous aspiration episodes. There is convincing evidence documenting that chronic, massive aspiration in patients with repaired EA/TEF is associated with the development of bronchiectasis. While chronic aspiration is likely associated with other CRM in patients with repaired EATTEF, this does not appear to have been confirmed by the data currently available. Prospective studies that systematically evaluate aspiration risk and allergic disease in patients with repaired EATTEF and document subsequent CRM will be needed to clarify the causes of CRM in this population. Given the prevalence of CRM, patients with repaired EA/TEF should ideally receive regular follow-up by multidisciplinary teams with expertise in this condition, throughout both childhood and adulthood.

Keywords: esophageal atresia with or without tracheoesophageal fistula, respiratory aspiration, tracheoesophageal fistula, esophageal atresia, gastroesophageal reflux

\section{INTRODUCTION}

Repaired esophageal atresia, typically associated with congenital tracheoesophageal fistula (EA/ $\mathrm{TEF}$ ), is commonly associated with long-term respiratory morbidity, including recurrent respiratory tract infection, chronic cough, persistently abnormal pulmonary function, and reported asthma $(1,2)$. There are many potential causes for respiratory complications in this population. Clinically significant tracheomalacia may occur in up to $78 \%$ of EA/TEF patients. In infants, tracheomalacia may lead to cyanotic spells (2). In children and adults, tracheomalacia may cause reduced airway clearance, leading to persistent bacterial bronchitis $(3,4)$. Patients with repaired EA/TEF have 
multiple, and sometimes interrelated risk factors for aspiration. Aspiration can be due to esophageal dysmotility, which is present in up to $75-100 \%$ of EA/TEF patients (2) or esophageal stricture. Gastroesophageal reflux disease (GERD) can also cause lung disease due to aspiration of gastric contents, and 35-58\% EA/TEF patients have been reported to experience GERD. Recurrent TEF may arise in about 9\% of EA patients. Laryngeal clefts (particularly types 1 and 2) and unilateral or bilateral vocal cord paresis or paralysis appears to be frequent in EA/TEF patients, and often leads to aspiration $(5,6)$. Vocal cord paresis or paralysis may be, in at least some cases related to EA/TEF corrective surgery (7). Thoracic large vessel malformations such as aberrant right subclavian artery also appear to be abnormally common in EA/ TEF patients, and may worsen tracheal and esophageal function, leading to dyspnea, dysphagia, and aspiration (8). Recent studies indicate that other esophageal diseases that impair esophageal function may also be commoner in patients with repaired EA/TEF, further increasing the risk of aspiration, including eosinophilic esophagitis, congenital esophageal stenosis, and heterotopic gastric mucosa in the esophagus $(9,10)$. Patients with repaired EA/TEF may also develop other respiratory conditions, such as atopy and asthma $(2,11)$; potentially due to altered gastrointestinal mucosal immunity, they may actually be at increased risk for these conditions. At present, the extent to which chronic respiratory morbidity (CRM) is due to aspiration early in life is unclear. This paper will attempt to summarize current knowledge of the degree to which aspiration is responsible for CRM in these patients.

\section{ASPIRATION}

Aspiration may be defined as the "inhalation of oral, gastric contents into lower respiratory tract." Its effect depends on whether the aspirate originates in the pharynx or stomach, whether it is liquid or solid, its $\mathrm{pH}$, the presence of bacteria, and, importantly, its volume and the chronicity of the aspiration. There is evidence that at least $50 \%$ healthy adults aspirate small volumes oropharyngeal secretions while asleep, but this is cleared by airway clearance including cough, and by the immune system, leaving no sequelae (12). Aspiration is a general term used to describe a spectrum of acute lung syndromes such as aspiration pneumonitis, aspiration pneumonia, and foreign body aspiration, as well as chronic pathology including diffuse aspiration bronchiolitis, bronchiectasis, organizing pneumonia, and bronchiolitis obliterans syndrome $(12,13)$. Aspiration pneumonitis (Mendelson's syndrome) is due to regurgitation of gastric contents in the presence of reduced consciousness such as anesthesia, leading to acute lung injury and/or acute respiratory distress syndrome. The aspirated fluid is typically sterile, at least initially, unless the gastric $\mathrm{pH}$ had previously been iatrogenically elevated (12). Aspiration pneumonia is caused by the aspiration of infected oropharyngeal secretions in patients who are at risk for aspiration. It is typically a patchy bronchopneumonia that, classically, is in the dependent lobes. Aspiration may lead to necrotizing bronchopneumonia and lung abscess formation (13).

Several research groups have described the pathology and radiology of chronic aspiration. Mukhopadhyay and Katzenstein reported the lung biopsy findings in 59 adults with aspiration pneumonia due to aspiration of particulate matter. Their mean age was 57 years, and, of interest to EA/TEF patients $32 \%$ of the cases had esophageal disease or a hiatus hernia. All of the specimens contained alveolar foreign material, including vegetable matter in $92 \%$ of cases, and giant cells were present. Eighty-eight cases had cryptogenic organizing pneumonia (bronchiolitis obliterans organizing pneumonia) with intraluminal fibroblast plugs in the small bronchioles and alveolar ducts, mainly associated with foreign body-type suppurative granulomas, and foci of bronchopneumonia. A few cases had interstitial foreign material with fibrosis (14). Cardasis et al. reported 25 adult patients with occult aspiration. Their mean age was 62 years. Ninety-six percent had GERD, 32\% had a hiatal hernia, and 40\% had other esophageal diseases. Biopsies revealed poorly formed granulomas near the bronchioles with evidence of chronic inflammation, and foreign body giant cells and lipoid pneumonia was common. On computerized tomography (CT) imaging, bronchial wall thickening, centrilobular nodules, and tree-in-bud opacities were observed. These were evident mainly in the lower lungs. A few cases had ground glass opacity, interstitial lung disease, or traction bronchiectasis (15). Pereira-Silva described an older patient population, consisting of 13 patients with chronic microaspiration. Their mean age was 71 years. Sixty-nine percent had GERD, $46 \%$ had a hiatus hernia, and $23 \%$ had esophageal dysfunction. CT scanning demonstrated centrilobular nodules and focal areas of ground glass opacity in all of the patients, and in $85 \%$, these findings were present in the dependent lung regions. Branching (tree-in-bud) opacities were common, and bronchiectasis was evident in 54\% (16). It has been reported that on pulmonary function testing (PFT), patients with chronic aspiration commonly have restrictive defects and a low diffusing capacity for carbon monoxide (DLCO) (17).

Aspiration is believed to contribute to a number of chronic lung diseases. Bronchiectasis is believed to be caused by aspiration in $4-18 \%$ of patients with non-CF bronchiectasis. El-Serag et al. studied 1,980 neurologically normal children with GERD and 7,920 controls. They reported that the odds ratio (OR) for bronchiectasis was $2.3(p<0.0001)$, and pneumonia was 2.3 $(p<0.02)$, among children with GERD (18). By contrast, Piccione et al. reported that in 66 patients with bronchiectasis diagnosed in a specialized Aerodigestive Clinic, aspiration-associated bronchiectasis was strongly associated with severe neurologic impairment. Bronchiectasis was also associated with parental report of GER, but not with the results of esophageal impedance studies or prior fundoplication (19). However, in this population with severe neurologic impairment, CRM may have been predominantly due to chronic aspiration of saliva (20), and the findings may be of less relevance to populations with aspiration predominantly due to other causes. In patients with bronchiolitis obliterans syndrome post-lung transplant, GERD appears to play an important role in worsening lung function, and lung function improves with fundoplication (21). In idiopathic pulmonary fibrosis, lung function is possibly worsened by GERD, particularly in scleroderma patients, who may also have esophageal dysfunction. In pulmonary fibrosis patients, there is some evidence that medical anti-reflux therapy may slow the decline in lung function (13). 


\section{CLINICAL FEATURES OF ASPIRATION}

Clinically, the diagnosis of aspiration may be obvious in the case of massive or witnessed choking, but often is under-recognized when due to subclinical microaspiration and misattribution of chronic cough, wheeze, and/or dyspnea.

\section{DIAGNOSING ASPIRATION}

Confirming whether aspiration is occurring remains medically challenging. Several tests are available, and they tend to have widely varying reported sensitivity and specificity.

The presence of aspiration is confirmed by lung biopsy showing evidence of a foreign body or foreign body granulomas (vide supra), a bronchoscopy demonstrating particulate matter, or when particulate matter is found in the bronchoalveolar lavage (BAL) fluid. Lipid from aspirated food or drinks is ingested by alveolar macrophages, and the presence of lipid-laden macrophages in the BAL has been proposed as evidence of aspiration. The latter may also be quantified as the BAL lipid-laden macrophage index (LLMI). This requires evaluation of 100 macrophages in the BAL, each of which is scored from 0 (no lipid) to 4 (completely opacified). The total is summed and can potentially range from 0 to 400 . A value over 100 has been considered as evidence of GERD with aspiration. However, necrosis of alveolar lining cells as a result of severe pneumonia also releases lipid from cell membranes into the BAL. As a result, while the LLMI has "been associated with chronic aspiration" its reported sensitivity varies from 57 to $100 \%$, and its specificity from 57 to $89 \%$ (21). Borrelli et al. observed that the LLMI was significantly higher in children with recurrent lung consolidation than in children with asthma $(p<0.05)$, and that the LLMI correlated with the number of reflux and non-acid reflux episodes, and number of episodes reaching the proximal esophagus $(p<0.01)$ on $\mathrm{pH}$-multichannel intraluminal impedance testing. The LLMI also significantly correlated with the number BAL neutrophils $(p<0.01)(23)$. By contrast, Rosen et al. found that in 50 children with a mean age of 6 years, the LLMI was not associated with $\mathrm{pH}$-impedance findings, endoscopic esophagitis, or clinical improvement following fundoplication (24). While BAL pepsin or bile acids have been proposed as markers of aspiration, they require further study (21). Exhaled breath condensate $(\mathrm{EBC})$ was investigated by Fitzpatrick et al. as part of a study of lansoprazole in 110 children with asthma. They found no association between $\mathrm{EBC}$ and esophageal $\mathrm{pH}$ probe results. Moreover, $\mathrm{EBC}$ acidity did not change with lansoprazole and the investigators concluded that $\mathrm{EBC}$ does not appear to be useful in the evaluation of the respiratory effects of GERD (25).

Bacterial culture of the BAL fluid may be a surprisingly useful marker of aspiration. Rosen et al. observed that in 46 children with chronic cough or wheezing, with a mean age 74 months, $26 \%$ had a positive BAL culture. Cultures grew mainly Streptococcus pneumoniae and Haemophilus influenza. The presence of a positive BAL culture was predicted by the amount of non-acid reflux or full-column GER on a $\mathrm{pH}$-impedance study, but not a history of pneumonia in previous 6 months. The presence of bacteria in the BAL may also reflect the effectiveness of mucociliary clearance of any aspirated material (26).
In the future, examination of the lower airway microbiome (ribosomal $16 \mathrm{~s}$ rRNA ecosystem) may be helpful. The lower airways of healthy people have been reported to have low levels of mainly oral bacteria such as Prevotella and Veillonella (27), but the microbiome of individuals with chronic aspiration has not been investigated to date.

\section{DETERMINING THE SOURCE OF ASPIRATION}

When there is convincing evidence of aspiration, determining its source may be difficult, and different tests may provide conflicting results.

Swallowing dysfunction can be demonstrated by videofluoroscopic swallowing study or, less commonly, fiberoptic endoscopic evaluation. Weir et al. reported that aspiration of thin liquids or post-swallow residue, seen on videofluoroscopic swallowing study, was associated with pneumonia in a broad group of pediatric patients (28). These types of studies have demonstrated that aspiration due to abnormal swallowing is common in EA/TEF patients $(29,30)$. Esophageal dysfunction can be diagnosed by an upper gastrointestinal (UGI) series or manometry. High-resolution manometry, demonstrating aperistalsis in EA/TEF patients, has been associated with CRM (29). Video manometry, particularly to evaluate a lack of coordination between pharyngeal contraction and relaxation of the upper esophageal sphincter, may also be helpful (31). Recent studies suggesting that laryngeal clefts and vocal cord paresis or paralysis are common in patients with EA/TEF indicate that careful otolaryngologic evaluation of the upper airway should be performed in EA/TEF patients suspected as having aspiration $(5,7)$. As thoracic vascular malformations may also compromise esophageal function in EA/TEF patients, complete cardiac evaluation of thoracic vessels should also be considered (8). A recurrent or persistent TEF is most often diagnosed by UGI with pull-back study. Many tests are available to diagnose GERD, including UGI, endoscopy, scintigraphy, and impedance/pH probe.

Borrelli et al. used $\mathrm{pH}$-multichannel intraluminal impedance to study 21 children, with a mean age of 4.1 years. They found that $49 \%$ of events were non-acid, $74 \%$ reached the proximal esophagus, and $80 \%$ of the episodes were liquid. The number of reflux episodes, non-acid reflux episodes, and non-acid reflux episodes reaching proximal esophagus were all significantly higher in children with recurrent lung consolidations than in children with asthma $(p<0.01)$ (23). Condino et al. performed these studies in 24 children with asthma and GERD, with a mean age of 33 months. They reported that $51 \%$ of events were nonacid. However, there was a low association with symptoms; for example, only $8 \%$ of events were associated with cough (32).

Ravelli et al. performed nuclear scintigraphy studies in 51 neurologically normal children with a median age of 6.5 years. GER to the upper $1 / 3$ of the esophagus was detected in $27 \%$ of the patients. Delayed gastric emptying (over $90 \mathrm{~min}$ ) was seen in $53 \%$, and aspiration on a 20 -h delayed scan was observed in $49 \%$ of children. However, this investigation correlated poorly with other tests. The number of reflux episodes did not differ in 
children with normal or abnormal pH studies. Seventy-five percent of the children who had aspiration on the delayed scan had a normal $\mathrm{pH}$ study, and few of them had histologic esophagitis. Aspiration was associated with CRM, with aspiration seen in $62 \%$ of children with recurrent pneumonia and all the infants with apnea. They felt that the sensitivity of the delayed scan was limited by the relatively short half-life of the technetium (33).

\section{GERD AND ASTHMA}

The largest repository of data regarding the association of aspiration with CRM concerns the possible link between GERD and asthma, with over 1,600 studies published. The possible relationship between GERD and asthma is potentially bidirectional, with asthma increasing the risk of GERD, and GERD increasing the severity of asthma. GERD may worsen asthma through a reflex mechanism, with stimulation of vagal nerves in the esophagus by acid, since some of these afferents end in same region of nucleus of the solitary tract where respiratory sensory nerves terminate (34), or through microaspiration, leading to bronchoconstriction and airway inflammation. Non-acid GER may be particularly harmful, as it would likely stimulate airway protective reflexes less. These relationships appear to be complex, with studies showing differing effects of reflux on asthma outcomes. For example, in one study of adults with asthma, omeprazole had no effect on methacholine challenge but did reduce cough sensitivity to capsaicin challenge in the patients who had $\mathrm{pH}$ probe-evidence of reflux (35). By contrast, another study observed a correlation between the number of esophageal reflux episodes and airway reactivity as evaluated by methacholine challenge (36).

In a systemic review, Thakkar et al. found that the prevalence of asthma in children with GERD was 13 versus $7 \%$ in controls (37). A systemic review in adults noted that the prevalence of GERD, using the Montreal definition, in adults with asthma was $58 \%$, compared to $38 \%$ in controls, giving an OR for GERD in adults with asthma of 5.5, and the OR for asthma in patients with GERD was 2.7 (36).

Several studies have evaluated whether GERD is associated with indicators of asthma control. In adults with poor asthma control, abnormal distal or proximal esophageal $\mathrm{pH}$ was associated with oral steroid use, and proximal reflux was associated with worse quality of life, but neither was associated with $\mathrm{FEV}_{1}$, asthma control, or methacholine challenge (38). By contrast, Kwiecien et al. noted that in 66 children with asthma with a mean age 10 years, night asthma symptoms were associated with a longer time spent at night with an esophageal pH below 4 (39).

Multiple studies have examined whether treating reflux improves asthma outcomes, although the results are contradictory. A study of esomeprazole in 828 adults with asthma and a positive GERD score resulted in very small, but statistically significant improvements in $\mathrm{FEV}_{1}$ and quality of life, but not in peak flow, exacerbations, or symptoms (40). In another, study of 207 adults with asthma and GERD symptoms, lansoprazole improved quality of life and reduced exacerbations needing prednisone, but had no effect on lung function or symptoms (41). In a Cochrane systematic review (mainly involving adults), anti-GERD therapy had no consistent effect on peak flows or symptoms (42). Reducing gastric acidity does not appear to be effective in children or adults with asthma and no GERD symptoms $(38,43)$.

It is important to recognize that proton pump inhibitors do not treat non-acid GER. Rothenberg and Cowles described a series of 235 children with asthma on prednisone who underwent laparoscopic Nissen fundoplication. Ninety percent reduced or stopped their steroids, $90 \%$ of children with night symptoms improved,

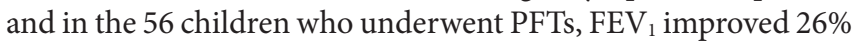
(44). However, this was a non-controlled, non-blinded study.

In summary, anti-GER therapy appears to improve asthma to some extent in patients with asthma and symptomatic GERD, although the outcomes which improved vary between studies. Some of the variation may be related to differences in how GERD was defined. It is unclear why a treatment effect was seen only in patients with symptomatic GERD.

\section{ASSOCIATIONS WITH RESPIRATORY MORBIDITY IN PATIENTS WITH REPAIRED EA/TEF}

Recurrent infection, aspiration, and atopic disease have been associated with CRM in EA/TEF patients. In 68 patients with type $\mathrm{C}$ EA/TEF, respiratory complications including recurrent pneumonia were associated with GERD in $74 \%$ of patients, with recurrent TEF in 13\%, and with esophageal strictures in $10 \%$ (45). Recurrent TEF has been associated with cough and with recurrent pneumonia (46). Bronchitis and pneumonia have been associated with dysphagia in 20 children with repaired EA/TEF (47). Shah et al. recently observed that early esophageal stricture formation was associated with recurrent pulmonary infections. GERD was associated with the subsequent performance of an aortopexy to treat severe tracheomalacia (9). A variety of studies have observed that PFT obstructive defects are associated with history of reported GERD (but not results of a $2-\mathrm{h} \mathrm{pH}$ probe), as well as choking spells during infancy, and pneumonia during the first 4 years of life $(48-50)$.

Several studies have specifically examined the relationship between GERD and CRM in patients with repaired EA/TEF. However, several of these studies were likely limited by variability in the objective assessment of GERD. In addition, research to date has been retrospective and may underestimate GERD early in life. Peetsold et al. examined the effect of anti-GERD surgery as a marker of past, chronic GERD (51). They reported that neither exercise capacity nor PFT restrictive defects were associated with anti-GERD surgery, but prior surgery was associated with a lower $\mathrm{FEV}_{1}$. Using prior anti-GERD surgery as a marker of chronic GERD may be problematic. Anti-GERD surgery is clearly performed because of ongoing, incompletely controlled GERD. However, surgery may prevent GERD from leading to CRM. Furthermore, depending on the degree to which esophageal function is impaired, fundoplication may actually worsen aspiration by causing retention of swallowed material in the esophagus, and oropharyngeal aspiration. Malmström found that in 23 adolescent EA/TEF patients, while $78 \%$ had a positive histamine challenge (used as a marker of airway reactivity), airway reactivity was not associated with esophageal symptoms, prior fundoplication, the number of previous reported pneumonias, 
the results of allergy testing, or physician diagnosis of asthma. Furthermore, airway reticular basement membrane thickening was not associated with gastrointestinal symptoms, esophageal biopsies, atopy, histamine challenge, or exhaled nitric oxide. In addition, PFT restrictive changes were not associated with current esophageal symptoms or past fundoplication (52). Similarly, Legrand et al. found that PFT abnormalities among 57 children with repaired EA/TEF were not associated with GERD symptoms or the results of objective testing, or with prior fundoplication (53). A small study of 267 -year olds with repaired EA/TEF had similar results, with no association between "esophageal symptoms" and PFT abnormalities, including lung clearance index (as a measure of small airway function). Furthermore, the results of 24-h $\mathrm{pH}$ probe were not associated with respiratory symptoms. Olbers et al. also noted that PFT abnormalities in this population could be due to tracheomalacia (54). Pedersen et al. did not find a significant association between abnormalities of esophageal function (determined by endoscopy and $\mathrm{pH}$ probe) or a history of recurrent pneumonia, and either obstructive or restrictive PFT defects (55). Sistonen et al. performed histamine challenges in 101 adult patients with repaired EA/TEF. Forty-one percent were positive, and, as expected in individuals with asthma, a positive challenge was associated with atopy or an elevated serum IgE. Unexpectedly, an elevated exhaled nitric oxide was not associated with atopy. While a positive histamine challenge was not associated with esophageal metaplasia on esophageal biopsy, PFT restrictive defects were (56).

Atopic disease, including asthma, may be commoner in EA/ TEF patients than in the general population. It is conceivable that chronic aspiration and/or recurrent lower respiratory infection early in life results in persistent airway inflammation and a risk of asthma and other airway diseases later on. In addition to the effects of chronic aspiration, it is possible that altered mucosal immunity in the gastrointestinal tract changes cellular immunity and increases the risk of atopy. Whether asthma in EA/TEF patients is secondary to the effects of aspiration or primary, asthma may cause chronic respiratory symptoms in older patients with EA/TEF. In 334 adult EA/TEF patients, persistent respiratory symptoms were associated with allergies or a family history of allergy (50). In children with EA/TEF and wheezing, 2/3 had a history of atopy (47). Allergies appear to be common in EA/ TEF patients. Malmström et al. reported that $15 \%$ of children with repaired EA/TEF had allergic rhinitis, and 54\% had positive allergy skin tests (52). In adults with repaired EA/TEF, 42\% had allergies, $37 \%$ had positive allergy tests, and $20 \%$ had a high serum IgE. Moreover, these findings were associated with current respiratory symptoms (56). Another smaller study of 28 adults with repaired EA/TEF found that increased airway reactivity, measured using methacholine challenge, was associated with serologic evidence of allergies and with elevated exhaled nitric oxide [generally an indicator of allergic airway inflammation (57)]. However, all of these tests were poorly associated with reported physician-diagnosed asthma (58). By contrast, while Robertson et al. found that methacholine challenge was positive in $48 \%$ of 18 EA/TEF patients, it was not associated with symptoms of atopy (59). Similarly, Pedersen et al. did not find that the frequency of allergies (measured by skin prick testing and by serum IgE), abnormal airway reactivity (measured by a mannitol challenge test), or abnormal exhaled nitric oxide differed between EA/TEF patients and a control group being evaluated for GERD (55).

Bronchiectasis is a potentially devastating long-term complication of EA/TEF (22). Using CT scanning, rates of bronchiectasis in EA/TEF survivors may be as high as $27 \%(4,55)$. While neither DeBoer et al. (4) nor Cartabuke et al. (60) examined potential associations with bronchiectasis (59), bronchiectasis in this population has generally been associated with massive aspiration, including patients with gastric or colonic interposition in a selected referral population (22), longstanding GERD (61), massive TEF pouch secretions, trisomy 21 (62), undiagnosed TEF (63), or broncho-esophageal fistula $(64,65)$.

\section{SUMMARY}

In the general population, bronchiectasis has been clearly associated with GERD and cryptogenic organizing pneumonia can result from chronic aspiration. The relationship between GERD and asthma is unclear, with various studies reporting conflicting asthma morbidities associated with GERD. In patients with repaired EA/TEF, GERD has been inconsistently associated with a low $\mathrm{FEV}_{1}$ and with PFT restrictive defects. Early studies have suggested that aspiration early in life in EA/TEF patients is associated with subsequent CRM. However, in more recent studies, while airway reactivity has been at least inconsistently associated with atopy in patients with repaired EA/TEF, increased bronchial hyper-reactivity has not shown to be associated with GERD. Based on a number of case reports and a small series, there is compelling evidence that bronchiectasis in patients with repaired $\mathrm{EA} / \mathrm{TEF}$ is typically due to massive, chronic aspiration. The lack of consistent evidence that aspiration leads to CRM in patients with repaired EA/TEF almost certainly reflects the variety of ways in which aspiration can be diagnosed, the retrospective nature of research to date, which may well underestimate the severity and chronicity of prior aspiration events, and the effects of previous treatment of aspiration, such as fundoplication. Ideally, prospective studies will be needed carefully documenting esophageal function and GERD, and subsequent CRM. This would likely be the most effective way of quantifying the extent to which aspiration influences subsequent pulmonary morbidity in this population. Research is also required to determine the best methods of diagnosing aspiration, assessing the effects of aspiration on the lower airway microbiome, and assessing whether altered gastrointestinal mucosal immunity affects atopy in these patients. Given the strong association of aspiration with cryptogenic organizing pneumonia and evidence that restrictive pulmonary defects are relatively common in EA/TEF survivors, evaluation by CT and/ or biopsy is needed to determine whether at least some of the restrictive impairments seen in patients with repaired EA/TEF are due to cryptogenic organizing pneumonia.

Until additional data are available, there is a compelling need for long-term follow-up of these patients, ideally by multidisciplinary expert teams, both during childhood and during adulthood $(4,66)$. Respiratory follow-up should include serial PFTs including spirometry, measurement of lung volumes, and, possibly, evaluation of bronchodilator responsiveness $(67,68)$. 
Chest radiography may be useful (59), and exercise testing and methacholine challenge should be considered when clinically indicated. If bronchiectasis is suspected, it is best diagnosed by CT of the chest. When bronchiectasis is confirmed, urgent evaluation of potential causes of aspiration should be carried out. Based on the evidence currently available, patients with repaired EA/TEF who have CRM should be evaluated for clinically significant tracheomalacia, as well as for aspiration due to swallowing dysfunction, GERD, and/or a recurrent or persistent TEF.

\section{REFERENCES}

1. Connor MJ, Springford LR, Kapetanakis VV, Giuliani S. Esophageal atresia and transitional care - step 1: a systematic review and meta-analysis of the literature to define the prevalence of chronic long-term problems. Am J Surg (2015) 209(4):747-59. doi:10.1016/j.amjsurg.2014.09.019

2. Kovesi T, Rubin S. Long-term complications of congenital esophageal atresia and/or tracheoesophageal fistula. Chest (2004) 126(3):915-25. doi:10.1378/ chest.126.3.915

3. Kompare M, Weinberger M. Protracted bacterial bronchitis in young children: association with airway malacia. J Pediatr (2012) 160(1):88-92. doi:10.1016/j. jpeds.2011.06.049

4. DeBoer EM, Prager JD, Ruiz AG, Jensen EL, Deterding RR, Friedlander JA, et al. Multidisciplinary care of children with repaired esophageal atresia and tracheoesophageal fistula. Pediatr Pulmonol (2016) 51(6):576-81. doi:10.1002/ ppul. 23330

5. Hseu A, Recko T, Jennings R, Nuss R. Upper airway anomalies in congenital tracheoesophageal fistula and esophageal atresia patients. Ann Otol Rhinol Laryngol (2015) 124(10):808-13. doi:10.1177/0003489415586844

6. Fraga JC, Adil EA, Kacprowicz A, Skinner ML, Jennings R, Lillehei C, et al. The association between laryngeal cleft and tracheoesophageal fistula: myth or reality? Laryngoscope (2015) 125(2):469-74. doi:10.1002/lary.24804

7. Morini F, Iacobelli BD, Crocoli A, Bottero S, Trozzi M, Conforti A, et al. Symptomatic vocal cord paresis/paralysis in infants operated on for esophageal atresia and/or tracheo-esophageal fistula. J Pediatr (2011) 158(6):973-6. doi:10.1016/j.jpeds.2010.12.006

8. Berthet S, Tenisch E, Miron MC, Alami N, Timmons J, Aspirot A, et al. Vascular anomalies associated with esophageal atresia and tracheoesophageal fistula. J Pediatr (2015) 166(5):1140-4. doi:10.1016/j.jpeds.2015.01.038

9. Shah R, Varjavandi V, Krishnan U. Predictive factors for complications in children with esophageal atresia and tracheoesophageal fistula. Dis Esophagus (2015) 28(3):216-23. doi:10.1111/dote.12177

10. Krishnan U, Mousa H, Dall'Oglio L, Homaira N, Rosen R, Faure C, et al. ESPGHAN-NASPGHAN guidelines for the evaluation and treatment of gastrointestinal and nutritional complications in children with esophageal atresia-tracheoesophageal fistula. JPediatr Gastroenterol Nutr (2016) 63(5):550-70. doi:10.1097/MPG.0000000000001401

11. Kovesi T. Long-term respiratory complications of congenital esophageal atresia with or without tracheoesophageal fistula: an update. Dis Esophagus (2013) 26(4):413-6. doi:10.1111/dote.12061

12. Marik PE. Aspiration pneumonitis and aspiration pneumonia. $N$ Engl J Med (2001) 344(9):665-71. doi:10.1056/NEJM200103013440908

13. Hu X, Lee JS, Pianosi PT, Ryu JH. Aspiration-related pulmonary syndromes. Chest (2015) 147(3):815-23. doi:10.1378/chest.14-1049

14. Mukhopadhyay S, Katzenstein AL. Pulmonary disease due to aspiration of food and other particulate matter: a clinicopathologic study of 59 cases diagnosed on biopsy or resection specimens. Am J Surg Pathol (2007) 31(5):752-9. doi:10.1097/01.pas.0000213418.08009.f9

15. Cardasis JJ, MacMahon H, Husain AN. The spectrum of lung disease due to chronic occult aspiration. Ann Am Thorac Soc (2014) 11(6):865-73. doi:10.1513/AnnalsATS.201310-360OC

16. Pereira-Silva JL, Silva CI, Araujo Neto CA, Andrade TL, Muller NL. Chronic pulmonary microaspiration: high-resolution computed tomographic findings in 13 patients. J Thorac Imaging (2014) 29(5):298-303. doi:10.1097/ RTI.0000000000000091

\section{AUTHOR CONTRIBUTIONS}

TK designed this paper, acquired the data, analyzed and interpreted the data, and gave final approval of the version submitted and any revised version.

\section{FUNDING}

No funding was received for this manuscript.

17. Fishman AP, Elias JA, Fishman JA, Grippi MA, Senior RM, Pack AI. Fishman's Pulmonary Diseases and Disorders. 4th ed. New York: McGraw (2008).

18. El-Serag HB, Gilger M, Kuebeler M, Rabeneck L. Extraesophageal associations of gastroesophageal reflux disease in children without neurologic defects. Gastroenterology (2001) 121(6):1294-9. doi:10.1053/gast.2001.29545

19. Piccione JC, McPhail GL, Fenchel MC, Brody AS, Boesch RP. Bronchiectasis in chronic pulmonary aspiration: risk factors and clinical implications. Pediatr Pulmonol (2012) 47(5):447-52. doi:10.1002/ppul.21587

20. Baikie G, South MJ, Reddihough DS, Cook DJ, Cameron DJ, Olinsky A, et al. Agreement of aspiration tests using barium videofluoroscopy, salivagram, and milk scan in children with cerebral palsy. Dev Med Child Neurol (2005) 47(2):86-93. doi:10.1111/j.1469-8749.2005.tb01096.x

21. Morehead RS. Gastro-oesophageal reflux disease and non-asthma lung disease. Eur Respir Rev (2009) 18(114):233-43. doi:10.1183/09059180.00002509

22. Banjar H. Bronchiectasis following repair of esophageal atresia and tracheo-esophageal fistula. Saudi Med J (2005) 26(10):1661-2.

23. Borrelli O, Battaglia M, Galos F, Aloi M, De Angelis D, Moretti C, et al. Non-acid gastro-oesophageal reflux in children with suspected pulmonary aspiration. Dig Liver Dis (2010) 42(2):115-21. doi:10.1016/j.dld.2009.06.011

24. Rosen R, Fritz J, Nurko A, Simon D, Nurko S. Lipid-laden macrophage index is not an indicator of gastroesophageal reflux-related respiratory disease in children. Pediatrics (2008) 121(4):e879-84. doi:10.1542/peds.2007-0723

25. Fitzpatrick AM, Holbrook JT, Wei CY, Brown MS, Wise RA, Teague WG, et al. Exhaled breath condensate $\mathrm{pH}$ does not discriminate asymptomatic gastroesophageal reflux or the response to lansoprazole treatment in children with poorly controlled asthma. J Allergy Clin Immunol Pract (2014) 2(5):579-86. doi:10.1016/j.jaip.2014.04.006

26. Rosen R, Johnston N, Hart K, Khatwa U, Katz E, Nurko S. Higher rate of bronchoalveolar lavage culture positivity in children with nonacid reflux and respiratory disorders. J Pediatr (2011) 159(3):504-6. doi:10.1016/j. jpeds.2011.05.021

27. Segal LN, Blaser MJ. A brave new world: the lung microbiota in an era of change. Ann Am Thorac Soc (2014) 11(Suppl 1):S21-7. doi:10.1513/ AnnalsATS.201306-189MG

28. Weir K, McMahon S, Barry L, Ware R, Masters IB, Chang AB. Oropharyngeal aspiration and pneumonia in children. Pediatr Pulmonol (2007) 42(11):102431. doi:10.1002/ppul.20687

29. Mahoney L, Rosen R. Feeding difficulties in children with esophageal atresia. Paediatr Respir Rev (2016) 19:21-7. doi:10.1016/j.prrv.2015.06.002

30. Yalcin S, Demir N, Serel S, Soyer T, Tanyel FC. The evaluation of deglutition with videofluoroscopy after repair of esophageal atresia and/or tracheoesophageal fistula. J Pediatr Surg (2015) 50(11):1823-7. doi:10.1016/j. jpedsurg.2015.07.002

31. Montgomery M, Witt H, Kuylenstierna R, Frenckner B. Swallowing disorders after esophageal atresia evaluated with videomanometry. J Pediatr Surg (1998) 33(8):1219-23. doi:10.1016/S0022-3468(98)90154-3

32. Condino AA, Sondheimer J, Pan Z, Gralla J, Perry D, O'Connor JA. Evaluation of gastroesophageal reflux in pediatric patients with asthma using impedance-pH monitoring. J Pediatr (2006) 149(2):216-9. doi:10.1016/j. jpeds.2006.03.022

33. Ravelli AM, Panarotto MB, Verdoni L, Consolati V, Bolognini S. Pulmonary aspiration shown by scintigraphy in gastroesophageal reflux-related respiratory disease. Chest (2006) 130(5):1520-6. doi:10.1378/chest.130.5.1520

34. Amarasiri DL, Pathmeswaran A, de Silva HJ, Ranasinha CD. Response of the airways and autonomic nervous system to acid perfusion of the esophagus 
in patients with asthma: a laboratory study. BMC Pulm Med (2013) 13:33. doi:10.1186/1471-2466-13-33

35. Ferrari M, Benini L, Brotto E, Locatelli F, De Iorio F, Bonella F, et al. Omeprazole reduces the response to capsaicin but not to methacholine in asthmatic patients with proximal reflux. Scand J Gastroenterol (2007) 42(3):299-307. doi:10.1080/00365520600883777

36. Havemann BD, Henderson CA, El-Serag HB. The association between gastro-oesophageal reflux disease and asthma: a systematic review. Gut (2007) 56(12):1654-64. doi:10.1136/gut.2007.122465

37. Thakkar K, Boatright RO, Gilger MA, El-Serag HB. Gastroesophageal reflux and asthma in children: a systematic review. Pediatrics (2010) 125(4):e925-30. doi:10.1542/peds.2009-2382

38. DiMango E, Holbrook JT, Simpson E, Reibman J, Richter J, Narula S, et al. Effects of asymptomatic proximal and distal gastroesophageal reflux on asthma severity. Am J Respir Crit Care Med (2009) 180(9):809-16. doi:10.1164/ rccm.200904-0625OC

39. Kwiecien J, Machura E, Halkiewicz F, Karpe J. Clinical features of asthma in children differ with regard to the intensity of distal gastroesophageal acid reflux. JAsthma (2011) 48(4):366-73. doi:10.3109/02770903.2011. 561513

40. Kiljander TO, Junghard O, Beckman O, Lind T. Effect of esomeprazole $40 \mathrm{mg}$ once or twice daily on asthma: a randomized, placebo-controlled study. Am J Respir Crit Care Med (2010) 181(10):1042-8. doi:10.1164/ rccm.200910-1537OC

41. Littner MR, Leung FW, Ballard ED II, Huang B, Samra NK; Lansoprazole Asthma Study Group. Effects of 24 weeks of lansoprazole therapy on asthma symptoms, exacerbations, quality of life, and pulmonary function in adult asthmatic patients with acid reflux symptoms. Chest (2005) 128(3):1128-35. doi:10.1378/chest.128.3.1128

42. Gibson PG, Henry RL, Coughlan JL. Gastro-oesophageal reflux treatment for asthma in adults and children. Cochrane Database Syst Rev (2003) 2:CD001496. doi:10.1002/14651858.CD001496

43. American Lung Association Asthma Clinical Research Centers, Mastronarde JG, Anthonisen NR, Castro M, Holbrook JT, Leone FT, et al. Efficacy of esomeprazole for treatment of poorly controlled asthma. N Engl J Med (2009) 360(15):1487-99. doi:10.1056/NEJMoa0806290

44. Rothenberg S, Cowles R. The effects of laparoscopic Nissen fundoplication on patients with severe gastroesophageal reflux disease and steroid-dependent asthma.J PediatrSurg(2012) 47(6):1101-4.doi:10.1016/j.jpedsurg.2012.03.013

45. Delius RE, Wheatley MJ, Coran AG. Etiology and management of respiratory complications after repair of esophageal atresia with tracheoesophageal fistula. Surgery (1992) 112(3):527-32.

46. Ghandour KE, Spitz L, Brereton RJ, Kiely EM. Recurrent tracheo-oesophageal fistula: experience with 24 patients. J Paediatr Child Health (1990) 26(2):89-91. doi:10.1111/j.1440-1754.1990.tb02393.x

47. Couriel JM, Hibbert M, Olinsky A, Phelan PD. Long term pulmonary consequences of oesophageal atresia with tracheo-oesophageal fistula. Acta Paediatr Scand (1982) 71(6):973-8. doi:10.1111/j.1651-2227.1982.tb09559.x

48. LeSouef PN, Myers NA, Landau LI. Etiologic factors in long-term respiratory function abnormalities following esophageal atresia repair. J Pediatr Surg (1987) 22(10):918-22. doi:10.1016/S0022-3468(87)80589-4

49. Agrawal L, Beardsmore CS, MacFadyen UM. Respiratory function in childhood following repair of oesophageal atresia and tracheoesophageal fistula. Arch Dis Child (1999) 81(5):404-8. doi:10.1136/adc.81.5.404

50. Chetcuti P, Phelan PD, Greenwood R. Lung function abnormalities in repaired oesophageal atresia and tracheo-oesophageal fistula. Thorax (1992) 47(12):1030-4. doi:10.1136/thx.47.12.1030

51. Peetsold MG, Heij HA, Nagelkerke AF, Deurloo JA, Gemke RJ. Pulmonary function impairment after trachea-esophageal fistula: a minor role for gastro-esophageal reflux disease. Pediatr Pulmonol (2011) 46(4):348-55. doi:10.1002/ppul.21369

52. Malmström K, Lohi J, Lindahl H, Pelkonen A, Kajosaari M, Sarna S, et al. Longitudinal follow-up of bronchial inflammation, respiratory symptoms, and pulmonary function in adolescents after repair of esophageal atresia with tracheoesophageal fistula. J Pediatr (2008) 153(3):396-401. doi:10.1016/j. jpeds.2008.03.034
53. Legrand C, Michaud L, Salleron J, Neut D, Sfeir R, Thumerelle C, et al. Longterm outcome of children with oesophageal atresia type III. Arch Dis Child (2012) 97(9):808-11. doi:10.1136/archdischild-2012-301730

54. Olbers J, Gatzinsky V, Jönsson L, Friberg LG, Abrahamsson K, Sillén U, et al. Physiological studies at 7 years of age in children born with esophageal atresia. Eur J Pediatr Surg (2015) 25(5):397-404. doi:10.1055/s-0034-1390017

55. Pedersen RN, Markow S, Kruse-Andersen S, Qvist N, Gerke O, Husby S, et al. Long-term pulmonary function in esophageal atresia-A case-control study. Pediatr Pulmonol (2016) 52(1):98-106. doi:10.1002/ppul.23477

56. Sistonen S, Malmberg P, Malmström K, Haahtela T, Sarna S, Rintala RJ, et al. Repaired oesophageal atresia: respiratory morbidity and pulmonary function in adults. Eur Respir J (2010) 36(5):1106-12. doi:10.1183/09031936.00153209

57. Kovesi T, Dales R. Exhaled nitric oxide and respiratory symptoms in a community sample of school aged children. Pediatr Pulmonol (2008) 43(12):1198-205. doi:10.1002/ppul.20927

58. Gatzinsky V, Wennergren G, Jönsson L, Ekerljung L, Houltz B, Redfors $\mathrm{S}$, et al. Impaired peripheral airway function in adults following repair of esophageal atresia. J Pediatr Surg (2014) 49(9):1347-52. doi:10.1016/j. jpedsurg.2013.12.027

59. Robertson DF, Mobaireek K, Davis GM, Coates AL. Late pulmonary function following repair of tracheoesophageal fistula or esophageal atresia. Pediatr Pulmonol (1995) 20(1):21-6. doi:10.1002/ppul.1950200105

60. Cartabuke RH, Lopez R, Thota PN. Long-term esophageal and respiratory outcomes in children with esophageal atresia and tracheoesophageal fistula. Gastroenterol Rep (Oxf) (2016) 4(4):310-4. doi:10.1093/gastro/gov055

61. Jayasekera CS, Desmond PV, Holmes JA, Kitson M, Taylor AC. Cluster of 4 cases of esophageal squamous cell cancer developing in adults with surgically corrected esophageal atresia - time for screening to start. J Pediatr Surg (2012) 47(4):646-51. doi:10.1016/j.jpedsurg.2011.09.065

62. Kang JB, Rothenberg SS, Krawiec ME, Sagel SD. Diagnosis of a symptomatic tracheal pouch by means of bronchoscopy after neonatal repair of a tracheoesophageal fistula. J Allergy Clin Immunol (2007) 120(3):541-3. doi:10.1016/j. jaci.2007.07.050

63. Behnia M, Tarver RD. Unilateral bronchiectasis and esophageal dysmotility in congenital adult tracheoesophageal fistula. Intern Med (2001) 40(7):620-3. doi:10.2169/internalmedicine.40.620

64. Dogan R, Farsak B, Yilmaz M, Tok M, Gungen Y. Congenital broncho-oesophageal fistula associated with bronchiectasis in adults. Report of two cases and review of theliterature. Respiration (1999) 66(4):361-5. doi:10.1159/000029390

65. Azoulay D, Regnard JF, Magdeleinat P, Diamond T, Rojas-Miranda A, Levasseur P. Congenital respiratory-esophageal fistula in the adult. Report of nine cases and review of the literature. J Thorac Cardiovasc Surg (1992) 104(2):381-4.

66. Bjornson CL, Mitchell I. Congenital tracheoesophageal fistula and coordination of care: expectations and realities. Paediatr Child Health (2006) 11(7):395-9. doi:10.1093/pch/11.7.395

67. Delacourt C, de BJ.Pulmonary outcome of esophageal atresia. JPediatr Gastroenterol Nutr (2011) 52(Suppl 1):S31-2. doi:10.1097/ MPG.0b013e318211609a

68. Beucher J, Wagnon J, Daniel V, Habonimana E, Fremond B, Lapostolle C, et al. Long-term evaluation of respiratory status after esophageal atresia repair. Pediatr Pulmonol (2013) 48(2):188-94. doi:10.1002/ppul.22582

Conflict of Interest Statement: The author declares that the research was conducted in the absence of any commercial or financial relationships that could be construed as a potential conflict of interest.

The reviewer YB and handling editor declared their shared affiliation, and the handling editor states that the process nevertheless met the standards of a fair and objective review.

Copyright $\odot 2017$ Kovesi. This is an open-access article distributed under the terms of the Creative Commons Attribution License (CC BY). The use, distribution or reproduction in other forums is permitted, provided the original author(s) or licensor are credited and that the original publication in this journal is cited, in accordance with accepted academic practice. No use, distribution or reproduction is permitted which does not comply with these terms. 